\title{
INTERVERTEBRAL DISC DEGENERATION AND REGENERATION: A MOTION SEGMENT PERSPECTIVE
}

\author{
B. Ashinsky ${ }^{1,2,3}$, H.E. Smith ${ }^{1,3}$, R.L. Mauck ${ }^{1,3,4}$ and S.E. Gullbrand ${ }^{1,3, *}$ \\ ${ }^{1}$ Translational Musculoskeletal Research Centre, Corporal Michael J. Crescenz VA Medical Centre, \\ Philadelphia, PA, USA \\ ${ }^{2}$ Drexel University School of Biomedical Engineering, Science and Health Systems, Philadelphia, PA, USA \\ ${ }^{3}$ Department of Orthopaedic Surgery, McKay Orthopaedic Research Laboratory, University of \\ Pennsylvania, Philadelphia, PA, USA \\ ${ }^{4}$ Department of Bioengineering, University of Pennsylvania, Philadelphia, PA, USA
}

\begin{abstract}
Back and neck pain have become primary reasons for disability and healthcare spending globally. While the causes of back pain are multifactorial, intervertebral disc degeneration is frequently cited as a primary source of pain. The annulus fibrosus (AF) and nucleus pulposus (NP) subcomponents of the disc are common targets for regenerative therapeutics. However, disc degeneration is also associated with degenerative changes to adjacent spinal tissues, and successful regenerative therapies will likely need to consider and address the pathology of adjacent spinal structures beyond solely the disc subcomponents. This review summarises the current state of knowledge in the field regarding associations between back pain, disc degeneration, and degeneration of the cartilaginous and bony endplates, the AF-vertebral body interface, the facet joints and spinal muscles, in addition to a discussion of regenerative strategies for treating pain and degeneration from a whole motion segment perspective.
\end{abstract}

Keywords: Nucleus pulposus, annulus fibrosus, cartilage endplate, interface, facet, spinal muscle, tissue engineering, physical therapy.

*Address for correspondence: Sarah E. Gullbrand, Ph.D., Corporal Michael J. Crescenz VA Medical Centre, Research, Building 21, Rm A214, 3900 Woodland Ave, Philadelphia, PA 19104, USA.

Email: sgullb@pennmedicine.upenn.edu

Copyright policy: This article is distributed in accordance with Creative Commons Attribution Licence (http://creativecommons.org/licenses/by-sa/4.0/).

\section{List of Abbreviations}

ADAMTS5

$\mathrm{AF}$

CEP

CGRP

COX-2

CT

DAPS

DRG

eDAPS

FAPs

GAG

iNOS

MMP

MRI

MSC

NGF

NP

$\mathrm{OA}$

ODI a disintegrin and metalloproteinase with thrombospondin motifs 5 annulus fibrosus cartilaginous endplate calcitonin gene-related peptide cyclooxygenase-2 computed tomography disc-like angle-ply structures dorsal root ganglion endplate-modified DAPS fibro-adipogenic progenitors glycosaminoglycan inducible nitric oxide synthase matrix metalloproteinase magnetic resonance imaging mesenchymal stem/stromal cells nerve growth factor nucleus pulposus osteoarthritis Oswestry disability index

$\begin{array}{ll}\text { PCL } & \begin{array}{l}\text { polycaprolactone } \\ \text { platelet-derived growth factor receptor } \beta \\ \text { secreted protein acidic and rich in }\end{array} \\ \text { SPARC } & \begin{array}{l}\text { cysteine } \\ \text { tropomyosin receptor kinase A }\end{array} \\ \text { TrkA } & \text { vertebral body } \\ \text { VB } & \text { micro-computed tomography }\end{array}$

\section{Introduction}

Low-back pain is the most common cause of disability globally, and in the USA is the numberone condition contributing to healthcare spending, totalling \$134.5 billion in 2016 alone (Dieleman et al., 2020). While the causes of back pain are complex and often include psychosocial factors, the anatomic structures within the spine are likely to be direct contributors to pain. The basic unit of the spine is the motion segment (Fig. 1), which consists of the intervertebral disc and adjacent cartilaginous endplates and bony vertebral bodies anteriorly, the 
neural structures including the spinal cord, cauda equina and nerve roots posteriorly, surrounded by the paraspinal muscles and bony elements including the facet joints (Raj, 2008). The intervertebral disc is composed of a central water- and proteoglycan-rich NP, encompassed circumferentially by the AF, which primarily consists of collagen type I fibres oriented at approximately $\pm 30^{\circ}$ to the long axis of the spine in alternating lamellae (Humzah and Soames, 1988). Degeneration of the intervertebral disc is commonly associated with back pain, and is characterised by a cascade of cellular, structural, compositional and mechanical alterations to the AF and NP tissues (American Academy of Orthopaedic Surgeons, 2008; Haefeli et al., 2006). However, degeneration of the disc is associated with, and potentially precipitated by, degenerative changes across the whole motion segment, and not solely the result of changes in the disc itself. This "whole motion segment" view of disc degeneration is less frequently studied compared to changes to the NP and AF alone. Understanding the cross-talk between spinal tissues during degeneration will not only advance the knowledge of disease pathogenesis, but may also aid in developing new and more efficacious treatments for disc degeneration and back pain. This review will detail what is known regarding structure-function alterations across the whole motion segment during degeneration, with a focus on the intervertebral disc interfaces with the vertebral body. Known associations will also be summarised between degeneration of non-disc structures (facet joints, muscle, vertebral bone) and disc degeneration and back pain, in addition to reviewing potential therapeutic strategies that treat degeneration from a whole motion segment perspective.

\section{Vertebral bodies and bony endplate}

The vertebral bodies of the spine consist of highly porous trabecular bone surrounded by a thin cortical shell. Adjacent to the disc, this cortical shell is referred to as the bony endplate, which ranges in thickness for

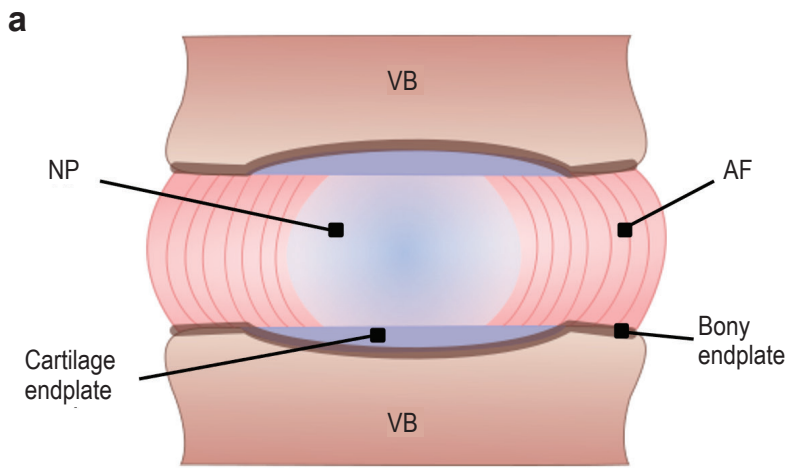

0.4 to $0.9 \mathrm{~mm}$ (Edwards et al., 2001). The thickness of the bony endplate is greatest in the lumbar vertebra, with the anterior shell thickness greater than the posterior in both endplates, cranial and caudal to the disc (Edwards et al., 2001). The bony endplate is thinnest and most porous in the central region of the vertebra adjacent to the NP (Edwards et al., 2001; Zehra et al., 2015) The caudal bony endplate has significantly more marrow contact pores than the cranial endplate (Martins et al., 2018).

The intervertebral discs are the largest avascular structures in the body, and thus cells within the disc rely on the vessels and marrow channels within the vertebral body as their primary source of nutrients. The blood supply to the vertebral body arises from pairs of segmental arteries, which branch from the aorta (Fig. 2a) (Crock and Yoshizawa, 1976). 10 to 20 periosteal arteries branch off the segmental arteries and traverse the surface of each vertebral body. The periosteal arteries give rise to several intra-osseous arteries, which form anastomoses and supply the centre of the vertebral body. The intra-osseous arteries extend additional anastomoses and form continuous capillary networks at both the inferior and superior ends of the vertebral body subchondral bone. At the bony endplate-disc junction, the capillaries form microvascular loops termed vascular buds (Fig. 2b-c) (Oki et al., 1996). The density of the vascular buds is greatest in the central region of the vertebral body, adjacent to the NP. In order to reach the cells at the disc centre, nutrients diffuse from the vascular buds, across the cartilage endplate, and then into the disc itself. Smaller solutes, including glucose, lactate, sulphate, and oxygen, were classically thought to rely on diffusion, whereas larger solutes rely on convection for transport (Katz et al., 1986; Maroudas et al., 1975; Urban et al., 1982). However, recent work has demonstrated that convective fluid flow can also impact the transport of small molecules into the disc (Gullbrand et al., 2015; Sampson et al., 2019). The vessels within the vertebral body are frequently accompanied by nerves adjacent to the vessel wall, with the highest density of nerves in the central vertebral body and a decreasing frequency towards the bony endplate (Bailey et al., 2011).

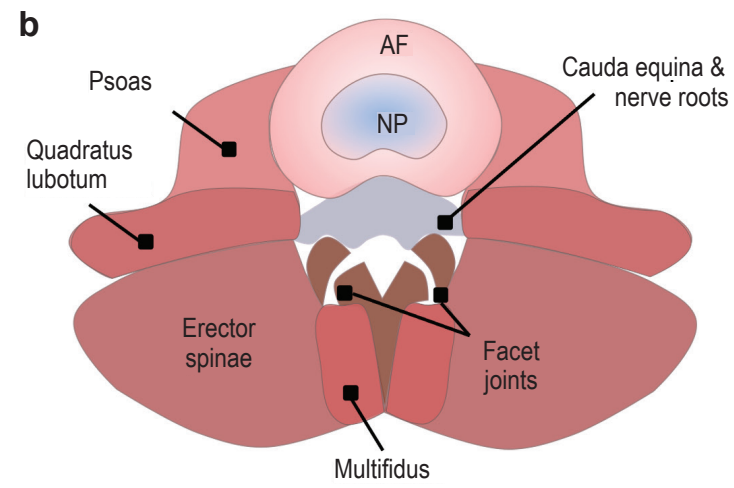

Fig. 1. Schematic of (a) coronal and (b) axial crossections of the spinal motion segment, demonstrating relevant anatomical regions. 

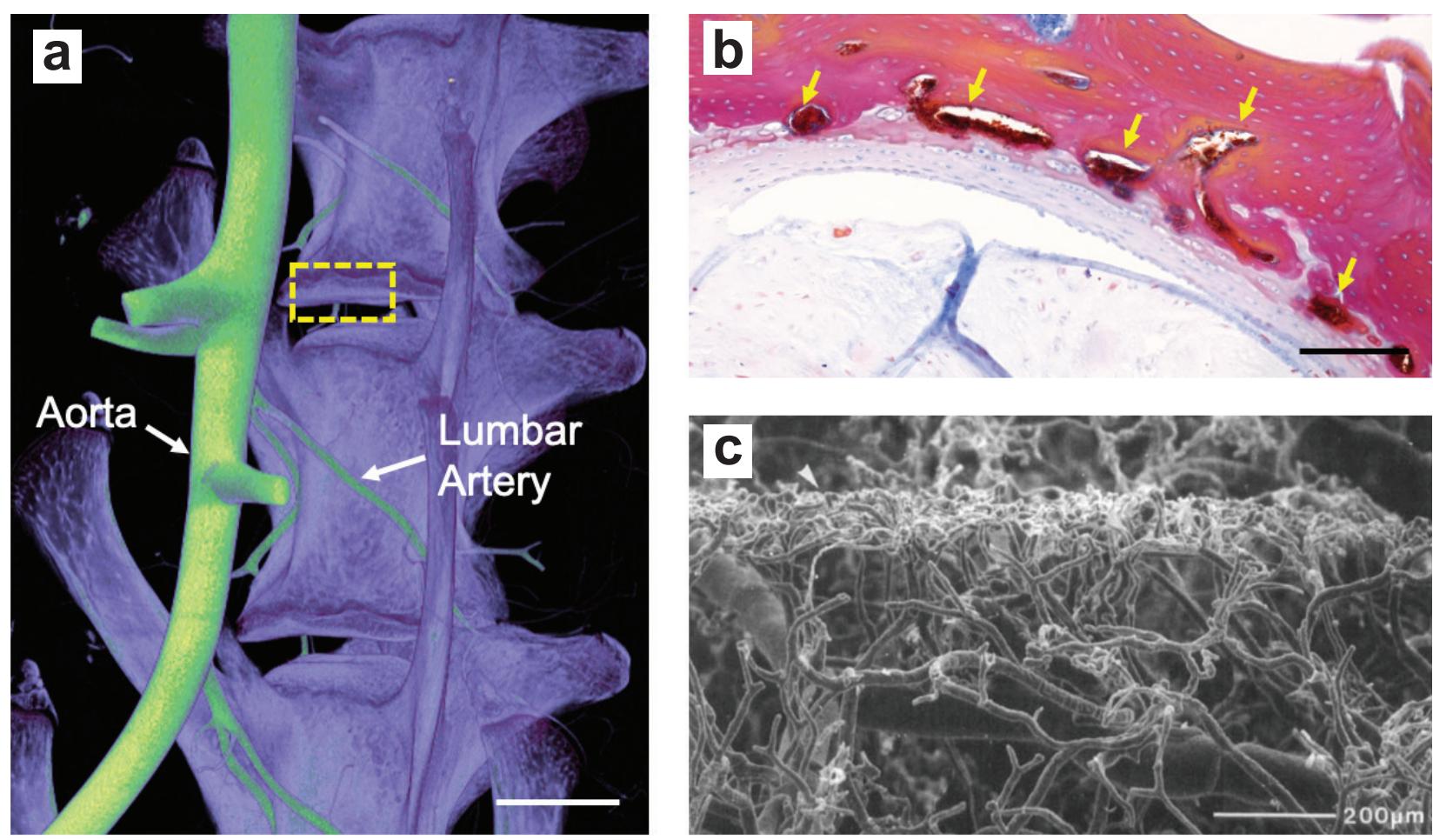

Fig. 2. Vertebral endplate vascular morphology. (a) $\mu \mathrm{CT}$ scan of the rabbit lumbar spine perfused with microFil (scale $=5 \mathrm{~mm}$ ). Dashed box highlights the bony endplate region shown in $\mathbf{b}$ and $\mathbf{c}$ (Ashinsky et al., 2020). (b) Mallory-Heidenhain trichrome stain of a sagittal section of the rabbit endplate-NP interface. Yellow arrows denote vessels (scale $=100 \mu \mathrm{m}$ ) (Ashinsky et al., 2020). (c) Scanning electron micrograph of a cast of the rabbit endplate vasculature (Oki et al., 1996). Images reproduced with permissions.

So-called "double endplate" structures are observed in the lower thoracic and lumbar spines (Fields et al., 2012; Edwards et al., 2001). These structures have a thinner superficial layer without compromising the biomechanical function of the endplate region, and so this feature may be an adaptation to increase nutrient availability to the avascular disc and protect against disc degeneration. Discs with double endplates have higher GAG content than discs with single layer endplates, after adjusting for age (Fields et al., 2012). Furthermore, the structural and mechanical properties of the bony endplate may be dictated by mechanical loading from the hydrostatic pressure of the adjacent NP. There is a positive linear correlation between disc fixed charge density and the stiffness of the adjacent vertebral bone, and an inverse relationship between intradiscal pressure and endplate porosity (Keller et al., 1993; Zehra et al., 2015).

Many studies have examined associations between disc degeneration and remodelling of the bony endplate and vertebral bone; however, much of this evidence is conflicting - with some studies suggesting sclerotic thickening and others suggesting thinning. For example, in studies of human cadaveric tissues, the bony endplate becomes thinner and more porous with increasing age and degeneration (Rodriguez et al., 2012; Wang et al., 2011). In a study of bone cross sections from human patients, a loss of bone from the central region of the bony endplate adjacent to the disc was associated with increased odds for disc height loss; however, severe disc height loss was significantly associated with increases in the bone mineral density of the superior and anterior regions (Kaiser et al., 2018). This study also found that bone mineral density, in the L3 vertebral body, declines more quickly in women than men, pointing to a confounding factor of sex when studying the association of bony changes with disc degeneration. These findings are in agreement with results from large cohort studies showing that disc degeneration is positively correlated with bone mineral density of the lumbar spine in female patients (Livshits et al., 2010), and inversely associated with osteoporosis (Pye, 2006). However, the relationship between vertebral bone changes and disc degeneration is likely to be complex and multifactorial, as mouse ovariectomy models provide evidence that osteoporosis may be associated with increased disc degeneration (Xiao et al., 2018).

In contrast, bony endplate remodelling has been reported in human cadaveric samples with mild degeneration (Thompson Grade II, Thompson et al., 1990). In this scenario, increases in bone volume and trabecular thickness were reported in the endplate with increasing degeneration, after adjusting for age, with these changes occurring primarily in the anterior regions.(Rutges et al., 2011; Simpson et al., 2001) In a cohort of samples from only male donors, disc degeneration (as measured by discography) was associated with greater endplate thickness but not higher bone mineral density.(Wang et al., 
2011) Occlusion of the bony endplate marrow and vascular channels also significantly correlated with disc degeneration as assessed morphologically and biochemically (Benneker et al., 2005). Furthermore, the maximum percentage of gadolinium enhancement on MRI images of the vertebral bone marrow is reduced with increasing age, suggesting that the vascular network within the vertebral body is compromised during ageing (Montazel et al., 2003). Since the endplate is considered to be the predominant route for nutrient and waste product transport into the vertebral body, a compromise of this nutritional pathway has long been hypothesised as a causative factor in disc degeneration (Maroudas et al., 1975; Nachemson et al., 1970; Urban et al., 1977).

Several animal models of disc degeneration also support the role of endplate remodelling and reduced disc nutrition in the degenerative cascade. The sand rat develops spontaneous disc degeneration, which is significantly associated with increases in endplate bone mineral density (Gruber et al., 2007; Gruber et al., 2008). In a rabbit annular puncture model, significant increases in bone volume fraction occur in the 12 weeks following needle puncture, and these changes were associated with reductions in endplate vascularity and small molecule transport into the degenerative disc (Ashinsky et al., 2020). Similar increases in endplate trabecular bone volume were observed in a sheep annular injury model, though this occurred at much longer time points (2 years) (Moore et al., 1996). Studies in ageing mice also demonstrated that endplate porosity is reduced with increasing age, and coincided with disc height loss (Cao et al., 2017). Notably, studies across multiple species demonstrated that the surgical or chemical disruption of the vertebral-endplate vessels could instigate degenerative changes to the disc, as assessed histologically (Feng et al., 2018; Imanishi et al., 2019; Kang et al., 2014; Yin et al., 2019), providing some mechanistic support for this hypothesis.

While alterations to the thickness and density of the bony endplate with degeneration remain unclear, changes within the vertebral body bone marrow and endplate defects have been consistently associated with both disc degeneration and back pain. In particular, the sizes of endplate defects correlate with the severity of disc degeneration and with worsening disability due to back pain, as measured by the ODI. Human patient endplates, having defects or erosions spanning at least $25 \%$ of the endplate area, were associated with a greater risk of progression of degeneration, and levels with progressive bone marrow changes were significantly associated with advanced grades of disc degeneration (Farshad-Amacker et al., 2017). These bone marrow changes, termed Modic changes, are bone marrow and endplate lesions identified due to signal intensity changes of these regions in T2- and T1-weighted MRIs (Zhang et al., 2008). The presence of Modic changes is frequently associated with the presence of back pain (Herlin et al., 2018). Studies of biopsy samples, taken during fusion procedures, suggest a fibrogenic and pro-inflammatory cross-talk between the disc and bone at levels showing Modic changes, with significant correlations between gene expression in the marrow and the adjacent discs (Dudli et al., 2017). Increased expression of pro-inflammatory cytokines has also been observed in discs adjacent to endplates with Modic changes (Schroeder et al., 2017). Additionally, the MRI T2 relaxation time of the vertebral bodies has been found to be significantly higher in back-pain patients compared to asymptomatic controls, adjusted for the presence of Modic changes and Pfirrmann grade, which may further point to early inflammatory processes (Lagerstrand et al., 2019).

\section{NP-CEP-bony endplate interface}

Adjacent to the vascular buds in the vertebral endplate, immediately bordering the NP, is the CEP. The CEP is a thin layer (0.6-1.2 mm thick) of hyaline-like cartilage whose collagen fibres run horizontally with respect to the spine axis, extending across the width to the inner AF (Roberts et al., 1989). The CEP is thinnest and most porous in the centre region, immediately adjacent to the NP (Wu et al., 2016). Fibres within the NP orient themselves perpendicularly and attach to the CEP by so-called "nodal insertions" (Brown et al., 2017; Wade et al., 2011).

The CEP also functions as a mechanical interface between the disc and the vertebral body, transmitting multiaxial forces between the two tissues. The CEP uniformly distributes the high intradiscal pressures generated from the NP over the surface of the vertebrae, preventing the highly pressurised NP from locally bulging into the underlying trabeculae (Brinckmann et al., 1983; Rolander and Blair, 1975). Therefore, the inherent structure and composition of the endplate play important roles in its biomechanical function, where thick and dense endplates are stronger than thin and porous ones (Langrana et al., 2006; Zhao et al., 2009). The CEP is composed primarily of type II collagen, proteoglycans, and water (Berg-Johansen et al., 2018c; Fields et al., 2014b; Fields et al., 2015; Roberts et al., 1989; Roberts et al., 1991). There is a composition gradient through the depth of the endplate, where proteoglycan and water content decrease and collagen content increases towards the vertebral bone. There is also compositional variation in the lateral plane, where the CEP adjacent to the inner AF has higher collagen and lower proteoglycan and water content than the region adjacent to the NP (Roberts et al., 1989).

With ageing and degeneration, the CEP undergoes several compositional changes that could reduce permeability and limit nutrient transport (Fig. 3). Specifically, Grant et al. (2016) measured higher 
calcium content in CEPs adjacent to more severely degenerated human discs and increasing levels of calcium diminished collagen and proteoglycan synthesis in cultured human CEP cells, by the activation of the extracellular calcium-sensing receptor. Calcium also enhances the cleavage of aggrecan by ADAMTS5, suggesting that higher calcium levels may promote CEP degeneration by increasing the activity of this aggrecanase. These findings are important since increased calcification and decreased proteoglycan content adversely impact tissue hydration and might, therefore, impede solute diffusion. Furthermore, recent advances in MRI, such as $\mathrm{T}^{*}$ relaxation time mapping, have facilitated the non-invasive visualisation of CEP hydration and collagen/GAG ratios (Fields et al., 2015). A recent study using live human patients and cadaveric spines suggested that CEP T2* values were associated with more severe disc degeneration, but only in younger individuals $(<50$ years old), further suggesting a link between CEP composition and disc degeneration (Wang et al., 2021).

The permeability of the CEP is at least an order of magnitude lower than that of the bony endplate (DeLucca et al., 2016; Rodriguez et al., 2011). Therefore, the diffusibility of solutes through the CEP might be the primary factor dictating the amount of nutrients and metabolites entering and exiting the disc. Calcification and dehydration of the CEP matrix, associated with degeneration, also can influence transport properties. Wong et al. (2019) showed that CEPs with poor diffusion have compositional deficits - such as increased amounts of collagen, aggrecan and minerals, as well as a lower cross-link maturity - that block solute passage. Further, these deficits to CEP transport have a negative effect on NP cell viability.

As with other cartilaginous tissues, the biochemical composition of the CEP dictates its mechanical properties. Endplate collagen content and collagen/ GAG ratios significantly influence tensile properties of the CEP (Fields et al., 2014b). As previously mentioned, CEP fibres are organised parallel to the vertebral body and NP, and finite element modelling indicated high-shear deformation of the CEP, which was attributed to significant lateral expansion of the NP (DeLucca et al., 2016). Since the CEP is poorly integrated with the vertebral body (Brown et al., 2017), it can become stripped off or avulse from the underlying trabecular bone at relatively low tensile loads (Berg-Johansen et al., 2018a; Berg-Johansen et al., 2018c). Additionally, the CEP and bony endplate interface lacks structural integrity, and the degree of detachment between the two structures has been shown to positively correlate with disc degeneration (Brown et al., 2017). This may suggest that detachment of the CEP from the bony endplate not only destabilises the motion segment at this local
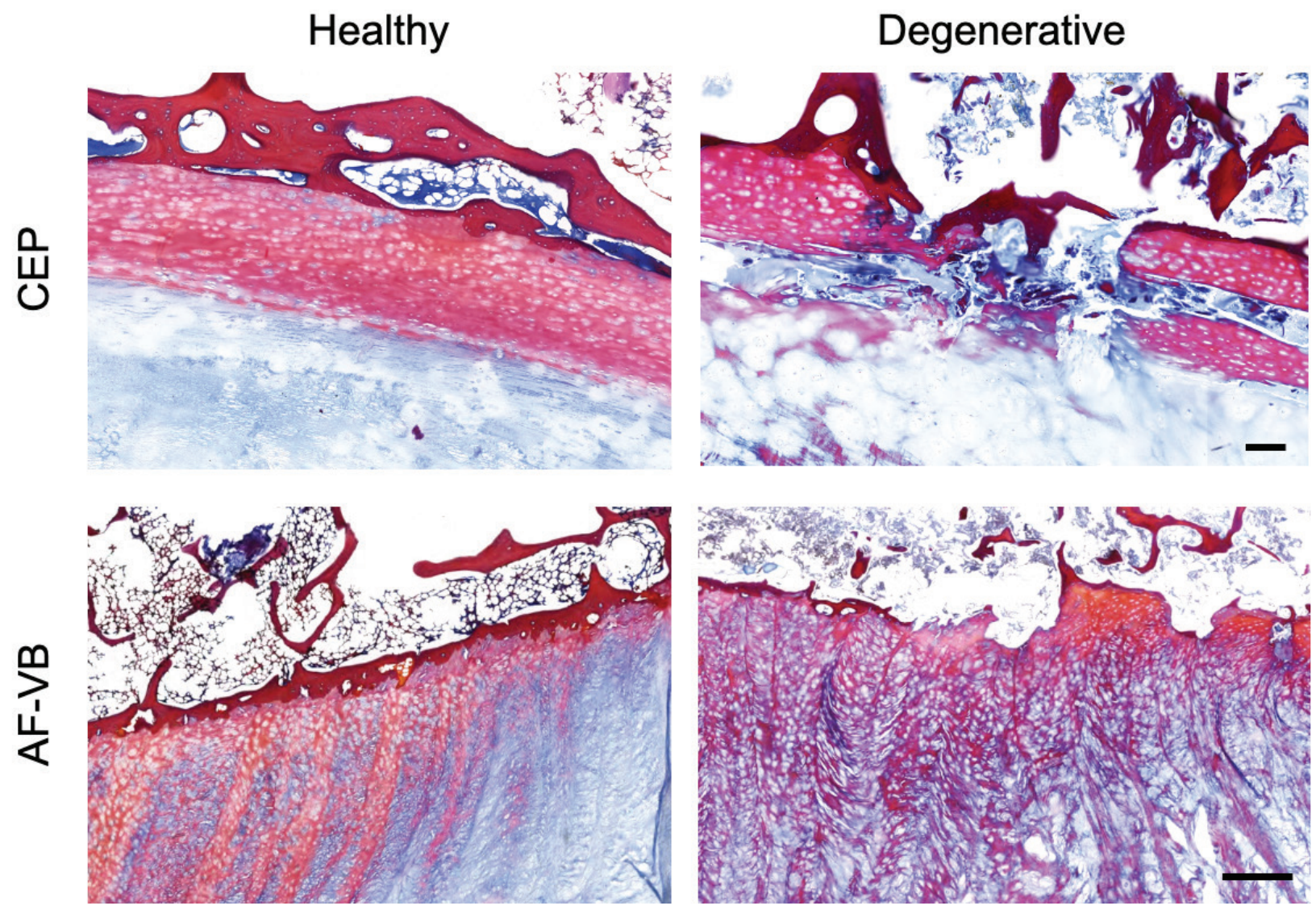

Fig. 3. Histology sections stained with the Mallory-Heidenhain trichrome stain of healthy and degenerative human intervertebral disc interfaces. CEP scale $=200 \mu \mathrm{m}, \mathrm{AF}-\mathrm{VB}$ scale $=800 \mu \mathrm{m}$. 
interface, but also may alter the mechanobiology within the disc, potentially further contributing to the degenerative cascade.

\section{AF-endplate interface}

The collagen fibres of the inner AF are continuous with those of the cartilaginous endplate (BergJohansen et al., 2018a). Fibres of the inner AF insert directly into the CEP and then into the bone for anchorage (Nosikova et al., 2012; Rodrigues et al., 2015). The strength and loading rate of the interface between the inner AF and cartilaginous endplate influences the failure strength and location. Under slow-loading rates, there is localised stretching of the AF (Veres et al., 2010). When the disc is loaded rapidly, the AF fibres have little time to recruit and realign. This results in annular displacements across the entire disc, particularly at the AF-CEP junction. At the outer $\mathrm{AF}$, the vertebral interface is formed by an enthesis, where the AF collagen fibres pass through a hyaline-like cartilage and then embed into a zone of calcified cartilage that is anchored to the subchondral bone (Nosikova et al., 2012). This complex interdigitation serves to minimise the stress concentrations during complex loading in tension, compression and shear (Berg-Johansen et al., 2018a). At the outermost AF, some of the collagen fibres from the lamella curve laterally to the outer aspect of the bone and merge directly with the periosteum of the vertebral body (Nosikova et al., 2012).

With injury, age or degeneration, the interface between the outer AF and the calcified cartilage layer of the endplate can separate, a condition termed a "tidemark avulsion" (Berg-Johansen et al., 2018c). This interface is significant, as there are marrow changes and increases in innervation of the vertebral bone adjacent to the avulsion (Fields et al., 2014a), which may contribute to the clinical symptoms of painful disc degeneration. The mechanism of tidemark avulsions is unclear, however. One biomechanical study of ex vivo bovine tissues reported that motion segments were more likely to exhibit tidemark avulsions in axial tension than in torsion (Rodrigues et al., 2015), suggesting that this failure may occur during bending when the AF is under tension. Another recent study evaluating endplate remodelling during degeneration in a rabbit model found that the endplate-AF interface undergoes progressive microscale stiffening, over time following AF puncture, as measured by atomic force microscopy (Ashinsky et al., 2020). This stiffening was accompanied by a substantial increase in organised collagen deposition along the interface over time, following injury. Current preliminary studies by the authors suggest that similar remodelling also occurs during human disc degeneration (Fig. 3). While the results from these animal studies shed an important light on the structural and functional alterations to the endplate-AF interface following a laboratory- controlled injury, literature evaluating this region during human idiopathic degeneration is sparse.

\section{Facet joints and spinal muscles}

The diarthrodial zygapophysial joints, or facet joints, are located posterior to the vertebral bodies, intervertebral disc and spinal nerves, and play a critical role in constraining spinal range of motion while aiding in the transmission of loads ( $\mathrm{O}^{\prime}$ Leary et al., 2018). In 1982, Kirkaldy-Willis described the concept of spinal degeneration in the context of instability, postulating a relationship between intervertebral disc and facet joint degeneration (Kirkaldy-Willis and Farfan, 1982). Facet OA is typically characterised by joint space narrowing, cartilage thinning and fissuring, subchondral sclerosis and osteophyte formation ( $\mathrm{Li}$ et al., 2011; O'Leary et al., 2018). Correlations have been established between disc degeneration and facet $\mathrm{OA}$, in addition to facet $\mathrm{OA}$ and endplate Modic changes (Li et al., 2011; Netzer et al., 2018; Paholpak et al., 2018; Suri et al., 2011). Facet and disc degeneration have also been positively correlated with instability of the spine during flexion extension movements, usually by increased anterior translation (Fujiwara et al., 2000; Kitanaka et al., 2018; Paholpak et al., 2018). As the facet joint synovial membrane is highly innervated, this instability has been postulated to contribute to spinal pain; however, the relationship between facet degeneration and back pain remains unclear. Although facet $\mathrm{OA}$ increases with increasing age and occurs at a high prevalence $(60 \%$ in men, $67 \%$ in women), no differences were found in the prevalence of facet $\mathrm{OA}$ in individuals with and without back pain (Kalichman et al., 2008). However, analysis of facet tissues from patients undergoing spinal fusion for back pain demonstrated significant increases in neovascularisation, neurogenesis and pro-inflammatory cytokine expression, compared to facets from healthy donor tissue (Kim et al., 2015). Significant increases in mRNA and protein levels for inflammatory pain mediators (iNOS and COX-2) and neuromodulators (CGRP, NGF and TrkA) were also observed, and this may prompt DRG neurons to increase pain sensitisation (Kim et al., 2015).

While disc and facet degeneration are correlated, the chronological relationship between the two remains unclear. In a study of human skeletal remains, a higher prevalence of facet osteophytes was noted compared to vertebral rim osteophytes at certain levels of the lumbar spine in individuals under the age of 40, suggesting that facet degeneration may precede disc degeneration (Eubanks et al., 2007). Studies of cadaveric tissue supported this hypothesis, with relatively healthy discs frequently exhibiting signs of facet degeneration involving fissuring of the cartilage surface (Li et al., 2011). However, a cross-section study of human patients concluded that, for most individuals, degeneration begins 
anteriorly (in the disc), though a small subset of the study population (10-20\%) do exhibit significant facet OA without disc degeneration (Suri et al., 2011). Indeed, in the authors' own studies of human cadaveric specimens, facets were observed adjacent to a Pfirrmann grade 5 disc with minimal obvious bony remodelling, and facets adjacent to a Pfirrmann grade 3 disc demonstrating substantial osteophyte formation (Fig. 4). Many of the studies on facet $\mathrm{OA}$ and disc degeneration, summarised here, are cross sectional in nature, making it difficult to draw cause and effect conclusions. While many studies are performed in vivo in human patients, this limits analysis to semi-quantitative scoring of degeneration based on MRI or CT images. Future longitudinal in vivo studies are clearly needed, in addition to more comprehensive structure-function analyses of human cadaveric tissues.

Associations between facet $\mathrm{OA}$, disc degeneration and the structure and function of the trunk musculature have also been explored. In a cohort of patients with low-back pain, patients with facet OA had a higher paraspinal muscle fat index compared to patients without facet OA, independent of age, body mass index and sex (Yu et al., 2017). Increasing disc degeneration is also associated with a larger fat signal fraction within the paraspinal muscles (Faur et al., 2019; Teichtahl et al., 2016; Urrutia et al., 2018). Recent work has also found an increase in the number of FAPs, accompanied by increased expression of adipogenic genes and $\alpha$-smooth-muscle actin in multifidus muscle samples from patients undergoing surgery for disc herniation, compared to control hamstring muscle from patients undergoing anteriorcruciate ligament reconstruction (Agha et al., 2020). Back pain is consistently correlated with reduced paraspinal muscle and psoas muscle cross-sectional areas, and reduced isometric strength of the trunk muscles compared to asymptomatic individuals (Danneels et al., 2000; Hides et al., 2008; Parkkola et al., 1993; Ploumis et al., 2011). On histology, marked degeneration of the multifidus muscle has been observed in biopsies from patients undergoing surgical treatment for back pain, with multifidus tissue from patients with acute back pain having an increased number of PDFGR $\beta$-positive cells and leukocytes compared to tissue from patients with chronic back pain (Shahidi et al., 2020). These findings are paralleled in disc injury models of degeneration across several species, where atrophy of the paraspinal muscles has been observed concomitant with the progression of disc degeneration, in addition to increased stiffness of the multifidus muscle (Brown et al., 2011; Hodges et al., 2006; Maas et al., 2018). Furthermore, damage to the cartilage endplate at the L4-L5 level is predictive of chronic low back pain when adjacent to paraspinal muscles with high fat fractions, further highlighting the interrelationships across spinal structures (Bailey et al., 2019).

\section{Strategies for regeneration from a whole-motion segment perspective}

To date, most efforts to address disc degeneration have focused on regenerative strategies for the $\mathrm{NP}$ and AF in isolation. Strategies for NP repair have focused largely on cell, growth factor, and hydrogel delivery, as reviewed by Tang et al. (2020) and Tendulkar et al. (2019). Strategies for AF repair encompass scaffolds or adhesives designed for herniation repair (Peredo et al., 2020; Sloan et al., 2018). However, as already summarised, intervertebral disc degeneration comprises a wide variety of pathologic changes to the adjacent disc interfaces, vertebral bone, facet joints and muscles, any number of which may contribute to back pain, and all of which impact one another. The following sections will focus on first reviewing cell-free regenerative approaches that may have the potential to impact all spinal tissues (i.e. physical therapy/anabolic mechanical loading). Then, cell-mediated regenerative approaches that harness vertebral bone-disc cross talk (i.e. cell homing), and those which aim to tissue engineer whole motion segment replacements (AF, NP and interface/ VB components) will be discussed. Ultimately,
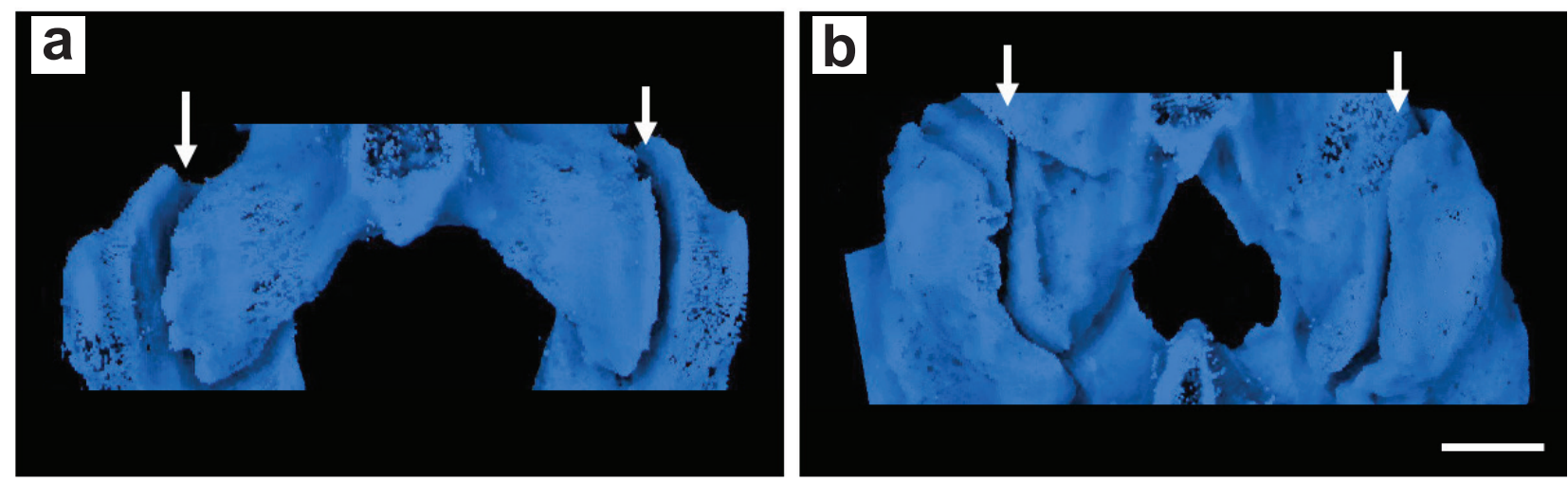

Fig. 4. Human facet joint degeneration. $\mu \mathrm{CT}$ scans of human facet joints (arrows) adjacent to the (a) L1-L2 disc, Pfirmman grade 5, from a 66 year old female, and (b) the L1-L2 disc, Pfirrmann grade 3, from a 65 year old male. Scale $=5 \mathrm{~mm}$. 
regenerative approaches that consider and address these concomitant changes may prove to be more efficacious than strategies that only seek to address a deficit and promote regeneration in only a single tissue within the spine.

\section{Cell-free approaches: physical therapy and anabolic loading}

Conservative therapy, including exercise and physical therapy regimens, is the first line of treatment for patients presenting to physicians with low-back pain. Physical therapy regimens can be clinically effective in managing back pain in some patients, particularly patient-specific programs delivered in a supervised manner (Hayden et al., 2005). Despite this, the biological effects of exercise and physical therapy on the spinal substructures remains understudied, particularly in human subjects.

Physical therapy and exercise subject the spine to cyclic mechanical loading. The effects of mechanical loading on the disc (AF and NP tissues) has been well characterised in vitro, ex vivo, and in vivo in live animal models. In vitro studies have shown that moderate cyclic loading has an anabolic effect on disc cells, while static super-physiological loading exhibits catabolic effects. High tensile strain applied to human disc cells in vitro has been shown to drive the cytokine and inflammatory responses associated with disc degeneration, as well as the neurotrophic factors associated with neoinnervation in low back pain (Gawri et al., 2014b). The effects of mechanical load on cell viability and extracellular matrix synthesis has been evaluated in several organ culture models; Illien-Jünger et al. (2010) reported that highfrequency loading and limited glucose availability results in upregulation of MMP13 gene expression and reduced cell viability in ex vivo ovine discs, without compensatory changes to GAG synthesis. However, organ culture models have also shown that physiological dynamic loading can promote type II collagen and aggrecan synthesis in chemically degraded bovine discs (Gawri et al., 2014a), and preserve cell viability and mechanical properties in healthy goat discs (Paul et al., 2012). This effect translates to the in vivo setting, where dynamic loading at physiological rates and magnitudes enhances anabolic remodelling of the disc, primarily by increased proteoglycan production (Korecki et al., 2008; MacLean et al., 2003; Walsh and Lotz, 2004; Wuertz et al., 2009). Distraction of the disc can mitigate degenerative changes induced by static compression in mice and rabbits (Kroeber et al., 2005; Lotz et al., 2008), indicating that tension may protect collagen from enzymatic degradation (Nabeshima et al., 1996). Running exercise in both healthy and degenerative rat discs increases cell proliferation in the stem cell niche consisting of the perichondrium of the vertebral body adjacent to the disc, and attenuates disc degeneration-associated mechanical allodynia (Luan et al., 2015; Sasaki et al., 2012). However, as disc degeneration is usually induced by artificial means (i.e. needle puncture or chronic static compression) in animal models, further study of the effects of anabolic loading in human subjects will be necessary. In a cross-sectional study in middle aged men, longterm runners had greater disc height and lower disc Pfirrmann grade compared to age-matched nonphysically active controls, although no differences in T2 relaxation times in the disc were found between groups, indicating similar levels of disc hydration (Mitchell et al., 2020).

In the disc, physical therapy regimens may also elicit a regenerative effect by the enhancement of convective fluid flow. In an in vivo rabbit model, low-rate dynamic loading increased the uptake and clearance of a small molecule MRI contrasting agent in both healthy and degenerative discs. This suggests that cyclic compression and distraction of the disc may benefit disc cell viability by increasing nutrient transport (Gullbrand et al., 2015). In a different study, Guehring et al. showed that daily distraction of rabbit discs can rehydrate the NP and upregulate gene expression of collagens and proteoglycans (Guehring et al., 2006). Additionally, Holm and Nachemson found that nutrient transport was increased during long term exercise and decreased following motion segment fusion in canines (Holm and Nachemson, 1982). In humans, a single session of lumbar joint mobilisation increased the diffusion of water into degenerative discs (Beattie et al., 2009); however, the relationship between enhanced disc nutrition and relief of symptoms warrants future investigation. Since nutrient and waste product exchange to and from the disc relies primarily on the integrity of the endplate, recapitulating healthy structure and function of the CEP could potentially promote disc health. Dolor et al. (2019) sought to increase solute transport across degenerative CEPs by treating human cadaveric CEPs with MMP-8, which reduced the matrix constituents that impede solute uptake. Increasing solute transport across the CEP also improved adjacent NP cell viability, suggesting that enhancing the transport properties of the CEP can improve disc health and nutrition. While these ex vivo studies are promising, how this treatment approach would be applied practically in vivo has yet to be determined.

Despite the breadth of knowledge on the effects of mechanical loading on disc tissues, the effects of anabolic loading induced by exercise or physical therapy on the facet joints and spinal muscles in the context of disc degeneration is severely understudied. From the study of other synovial joints, it is known that physiological loading can have anabolic effects on articular cartilage characterised by increased cell proliferation and extracellular matrix production - an effect which should translate to facet cartilage (Jaumard et al., 2011). However, an organ culture model utilising whole rabbit functional spinal units demonstrated that cyclic flexion-extension loading elicited a pro-inflammatory response in facet joint cartilage characterised by increased gene expression 
of COX-2 and MMP-1, with no significant changes in aggrecan gene expression (Hartman et al., 2015). Further work is needed on facet joints, investigating alternate loading modalities, magnitudes and frequencies, as well as assaying additional anabolic outputs. In skeletal muscle, exercise is known to increase collagen synthesis rates and have broad anti-inflammatory effects (Miller et al., 2005; Petersen and Pedersen, 2005). Work in the SPARC null mouse model, which exhibits spontaneous disc degeneration, demonstrated that fibrotic remodelling and inflammation of the multifidus muscle could be successfully attenuated with physical activity (James et al., 2018; James et al., 2019). In human patients, exercise programmes generally lead to an increase in trunk muscle size, particularly those programs using machine-based resistance exercises or programmes utilising motor control exercises combined with nonmachine based resistance exercises (Shahtahmassebi et al., 2014). However, the effects on muscle quality are less clear, with evidence in small cohorts of low-back pain patients that fatty infiltration of the paraspinal muscles is either slightly decreased or unchanged with exercise therapy (Berry et al., 2019; Welch et al., 2015).

\section{Cell and tissue engineering strategies: cell homing and motion segment tissue engineering} Although exercise and physical therapy may provide some inherent regenerative effect, in patients with more advanced degeneration, the resident population of AF and NP cells may be incapable of mounting a sufficient regenerative response. Increased cell senescence (Le Maitre et al., 2007; Patil et al., 2018), combined with the inflammatory milieu present in the degenerative disc (Maidhof et al., 2014; Molinos et al., 2015; Shamji et al., 2010), may further limit the capacity of resident cells to mount a regenerative response. To mitigate this, recruiting, or homing of MSCs has been explored as a mechanism for maintaining tissue homeostasis and promote endogenous repair in several musculoskeletal tissues. This approach aims to exploit the inherent regenerative capacity of MSCs, whereby MSCs are mobilised from their niche outside of the disc in response to injurious signals and chemical mediators (Sakai et al., 2012). Potential stem cell niches have been identified in the perichondrium of the vertebral body, adjacent to the disc and at the insertion of the outer AF into the vertebral body (Henriksson et al., 2009). In the disc, exogenously delivered bone-marrow-derived MSC migration through the endplate has been described as a potential therapeutic for stimulating endogenous disc-cell repair in organ culture models (Illien-Jünger et al., 2012; Pereira et al., 2014; Pereira et al., 2016; Vadalà et al., 2013; Wangler et al., 2019). These studies demonstrate that MSCs can migrate through degenerative disc tissues (Illien-Jünger et al., 2012). These 'homed' MSCs promoted matrix remodelling, with longer lasting and sustained effects than exogenous delivery of MSCs directly to the disc
(Clouet et al., 2019; Pereira et al., 2016; Wangler et al., 2019). Such MSC mobilisation and homing techniques could be combined with exercise or physical therapy to further encourage regeneration, although future in vivo investigations in this area are called for.

The aforementioned strategies based on physical therapy, enhancing disc nutrition, and cell homing are only likely to be effective in cases of mild to moderate degeneration. In cases of severe degeneration, more invasive strategies will probably be required to functionally regenerate or replace the disc and surrounding tissues. Over the past decade, there has been an emerging interest in the field to tissue engineer complete discs by combining cells and biomaterials to recapitulate the form and function of the native tissue. Several groups have produced composite engineered discs with only AF and NP components (Bowles et al., 2011; Moriguchi et al., 2017); however, far fewer constructs have been developed that incorporate cartilage or bony endplate analogues to comprise a whole motion segment (Fig. 5) (Gullbrand et al., 2018b).

The authors' group has developed tissue engineered DAPS composed of an alternating, orientated electrospun PCL AF analogue and a hydrogel NP region, and extensively evaluated this design in both in vitro and in vivo settings (Martin et al., 2014; Martin et al., 2017a; Martin et al., 2017b; Nerurkar et al., 2010). When implanted into the rat caudal disc space, cell-seeded DAPS motion segments achieved mechanical properties equivalent to native values, though the NP region showed a progressive loss of proteoglycan content and there was little evidence of DAPS integration with the adjacent vertebral bodies. To address these limitations, acellular PCL foams were apposed to the DAPS, serving as endplate analogues, which substantially improved their short-term in vivo performance. This advance underscored the importance of addressing the bone-disc interface in a tissue engineered construct. Improved outcomes included maintenance of T2 MRI signal and proteoglycan content, as well as evidence of integration with the native vertebral body, as observed by $\mu \mathrm{CT}$ and histology (Martin et al., 2017a). These eDAPS were further evaluated for in vivo integration and mechanical function in the rat caudal spine, and demonstrated near-native tensile and compressive mechanical properties by 20 weeks (Gullbrand et al., 2018a). Improvements in tensile mechanics over time in vivo were accompanied by an increase in maturation of the interface between the adjacent vertebral body and the endplate, where host cells deposited collagen and began to mineralise and vascularise in the endplate region. This work was later translated to a large animal model, where the eDAPS were evaluated in the goat cervical spine, which has a length scale similar to the human cervical spine (Gullbrand et al., 2018a). Results from that study illustrated that, after 4 weeks of implantation, the eDAPS maintained or improved in terms of matrix distribution, and at 8 weeks, the eDAPS compressive 
a

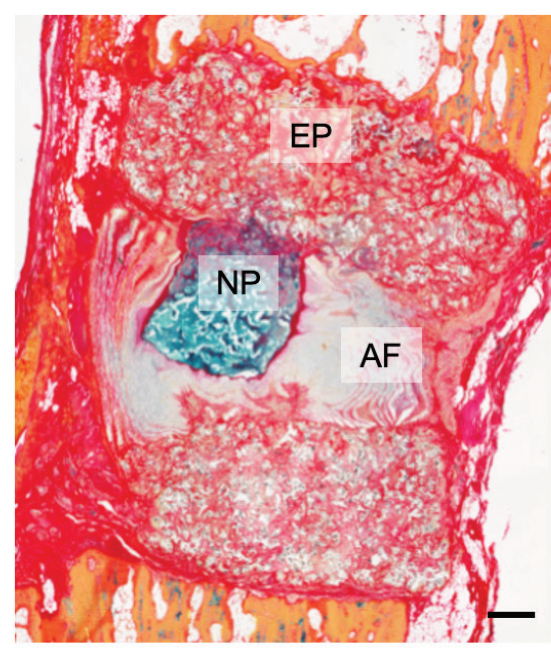

b

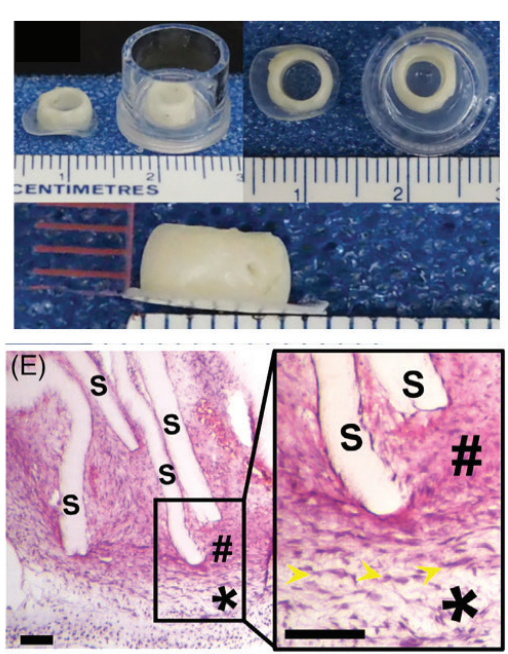

C

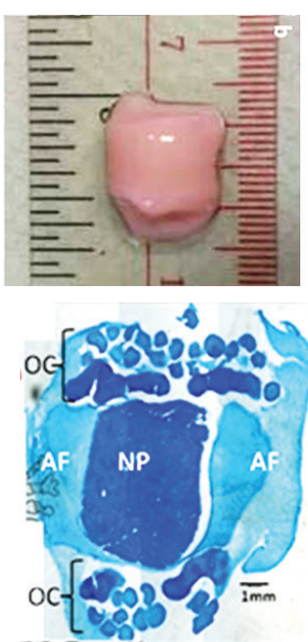

Fig. 5. Examples of tissue engineered disc implants with endplate interfaces from the literature. (a) Endplate-modified disc-like angle ply structures after 20 weeks implantation in the rat tail (Gullbrand et al., 2018a). (b) A tissue engineered CEP-AF interface. $S=$ scaffold, $\#=$ outer $A F,{ }^{*}=$ cartilage, yellow arrow heads $=$ directional orientation of outer AF cells (Chong et al., 2020). (c) A tissue engineered whole disc replacement with an osteochondral endplate component (Chik et al., 2015). Images reproduced with permission.

mechanical properties either matched or exceeded that of the native disc.

Others in the field have designed whole, tissue engineered motion segments utilising aligned polycarbonate urethane scaffolds for the AF region, combined with an NP hydrogel and calcium phosphate endplate composite (Iu et al., 2017a; Iu et al., 2017b). In vitro, these constructs demonstrated component integration and mechanical stability, as determined by a pushout test. However, peel tests indicated that the engineered AF lamellae were an order of magnitude weaker than native AF after 2 weeks of culture (Iu et al., 2017a). Although the interfacial strength between the AF and NP matured between 1 and 2 weeks of culture, they did not continue to functionally mature beyond 2 weeks. When these composites were implanted into a localised bone-disc defect in the bovine tail, all of implants subsided into bone and there was no identifiable NP tissue present after 1 month. Notably, however, the engineered AF layers were still adherent to one another and to the bone substitute material. Chong et al. (2020) attempted to recapitulate the AFcartilage endplate interface in vitro. Bovine outer AF cells seeded on a multilamellar polycarbonate urethane scaffold were cocultured with articular chondrocytes to recapitulate the cartilage endplate. After 2 weeks in vitro, collagen I and II and aggrecan immunohistochemical staining distributions were similar to the native interface, and tensile strength increased over time in culture.

Chik et al. (2015) developed a multiphasic construct consisting of two osteochondral subunits, an NPlike core and a multi-lamellae AF-like component and evaluated its performance following in vitro culture with a compressional-torsional bioreactor. Although this study only evaluated construct in vitro performance, it importantly assessed the diffusivity of the endplate analogue, which is a critical feature for recapitulating nutritional function. They reported that the osteochondral subunits enabled passive nutrient diffusion, which in turn, supported the viability of NP cells. While promising, these constructs will need to be evaluated in vitro and in vivo at larger size scales, which may pose a more substantial nutritional challenge. Overall, there has been continued progress toward whole-disc regenerative replacement techniques for advanced stage degeneration, but more work is needed to understand how these constructs will fare at largesize scales and in a degenerative environment.

As mentioned previously, facet joint changes have also been reported to occur concomitant with disc degeneration and as such, facet joint repair will be an important consideration when addressing whole motion segment replacement. Arthroplasty prostheses have been described (McAfee et al., 2007; Phillips et al., 2009; Sjovold et al., 2012; Wilke et al., 2006; Zhu et al., 2007), as has a facet joint resurfacing system (Anekstein et al., 2015; de Kelft, 2016). However, only limited preliminary data exist that support that these devices result in improved functionality and reduced pain. Additionally, both systems are susceptible to device-related failure or implant dislocation that commonly require reoperation with posterior lumbar interbody fusion. Despite similar joint pathology to OA, facet tissue engineering remains almost completely unexplored (O'Leary et al., 2018). The future application of anatomical osteochondral tissue-engineering approaches to the facet may provide a much-needed, long-term, motion-preserving solution (Daly et al., 2019; Grayson et al., 2008; Hung et al., 2003). 


\section{Conclusions}

It is evident that disc degeneration is associated with pathologic alterations to the disc interfaces, as well as the adjacent vertebral bone, facet joints and paraspinal muscles, all of which may contribute to pain in patients. However, these tissues are frequently studied in isolation, and there remain significant gaps in knowledge regarding the mechanism by which degenerative changes occur concomitantly across these substructures. Further study of the crosstalk between spinal tissues during degeneration and regeneration is warranted, particularly using in vivo animal models and human subjects where possible. Treatment of degeneration from a whole motion segment perspective also has the potential to improve the efficacy of new therapeutics and lead to improved quality of life for patients suffering from back pain. Finally, while this review is focused on the musculoskeletal tissues of the spine, further study on the contributions of systemic factors at the whole patient level (such as environmental and psychosocial factors) to degeneration and pain is also warranted.

\section{References}

Agha O, Mueller-Immergluck A, Liu M, Zhang H, Theologis AA, Clark A, Kim HT, Liu X, Feeley BT, Bailey JF (2020) Intervertebral disc herniation effects on multifidus muscle composition and resident stem cell populations. JOR Spine 3: e1091. DOI: 10.1002/ jsp2.1091.

American Academy of Orthopaedic Surgeons (2008) The burden of musculoskeletal diseases in the United States. Rosemont, IL, USA. ISBN 978-0-89203533-5.

Anekstein Y, Floman Y, Smorgick Y, Rand N, Millgram M, Mirovsky Y (2015) Seven years followup for total lumbar facet joint replacement (TOPS) in the management of lumbar spinal stenosis and degenerative spondylolisthesis. Eur Spine J 24: 23062314.

Ashinsky BG, Bonnevie ED, Mandalapu SA, Pickup S, Wang C, Han L, Mauck RL, Smith HE, Gullbrand SE (2020) Intervertebral disc degeneration is associated with aberrant endplate remodeling and reduced small molecule transport. J Bone Miner Res 35: 1572-1581.

Bailey JF, Fields AJ, Ballatori A, Cohen D, Jain D, Coughlin D, O'Neill C, McCormick Z, Han M, Krug R, Demir-Deviren S, Lotz JC (2019) The relationship between endplate pathology and patient-reported symptoms for chronic low back pain depends on lumbar paraspinal muscle quality. Spine (Phila Pa 1976) 44: 1010-1017.

Bailey JF, Liebenberg E, Degmetich S, Lotz JC (2011) Innervation patterns of PGP 9.5-positive nerve fibers within the human lumbar vertebra. J Anat 218: 263-270.
Beattie PF, Donley JW, Arnot CF, Miller R (2009) The change in the diffusion of water in normal and degenerative lumbar intervertebral discs following joint mobilization compared to prone lying. J Orthop Sports Phys Ther 39: 4-11.

Benneker LM, Heini PF, Alini M, Anderson SE, Ito K (2005) 2004 young investigator award winner: vertebral endplate marrow contact channel occlusions and intervertebral disc degeneration. Spine (Phila Pa 1976) 30: 167-173.

Berg-Johansen B, Fields AJ, Liebenberg EC, Li A, Lotz JC (2018a) Structure-function relationships at the human spinal disc-vertebra interface. J Orthop Res 36: 192-201.

Berg-Johansen B, Han M, Fields AJ, Liebenberg EC, Lim BJ, Larson PE, Gunduz-Demir C, Kazakia GJ, Krug R, Lotz JC (2018b) Cartilage endplate thickness variation measured by ultrashort echo-time MRI is associated with adjacent disc degeneration. Spine (Phila Pa 1976) 43: E592-E600.

Berg-Johansen B, Jain D, Liebenberg EC, Fields AJ, Link TM, O'neill CW, Lotz JC (2018c) Tidemark avulsions are a predominant form of endplate irregularity. Spine (Phila Pa 1976) 43: 1095-1101.

Berry DB, Padwal J, Johnson S, Englund EK, Ward SR, Shahidi B (2019) The effect of high-intensity resistance exercise on lumbar musculature in patients with low back pain: a preliminary study. BMC Musculoskelet Disord 20: 290. DOI: 10.1186/s12891019-2658-1.

Bowles RD, Gebhard HH, Härtl R, Bonassar LJ (2011) Tissue-engineered intervertebral discs produce new matrix, maintain disc height, and restore biomechanical function to the rodent spine. Proc Natl Acad Sci U S A 108: 13106-13111.

Brinckmann P, Frobin W, Hierholzer E, Horst M (1983) Deformation of the vertebral end-plate under axial loading of the spine. Spine (Phila Pa 1976) 8: 851-856.

Brown S, Rodrigues S, Sharp C, Wade K, Broom N, McCall IW, Roberts S (2017) Staying connected: structural integration at the intervertebral discvertebra interface of human lumbar spines. Eur Spine J 26: 248-258.

Brown SHM, Gregory DE, Carr JA, Ward SR, Masuda K, Lieber RL (2011) ISSLS prize winner: adaptations to the multifidus muscle in response to experimentally induced intervertebral disc degeneration. Spine (Phila Pa 1976) 36: 1728-1736.

Cao Y, Liao S, Zeng H, Ni S, Tintani F, Hao Y, Wang L, Wu T, Lu H, Duan C, Hu J (2017) 3D characterization of morphological changes in the intervertebral disc and endplate during aging: a propagation phase contrast synchrotron microtomography study. Sci Rep 7: 1-12.

Chik TK, Chooi WH, Li YY, Ho FC, Cheng HW, Choy TH, Sze KY, Luk KKD, Cheung KMC, Chan BP (2015) Bioengineering a multicomponent spinal motion segment construct - a 3D model for complex tissue engineering. Adv Healthc Mater 4: 99-112. 
Chong JE, Santerre JP, Kandel RA (2020) Generation of an in vitro model of the outer annulus fibrosus-cartilage interface. JOR Spine 3: e1089. DOI: 10.1002/jsp2.1089.

Clouet J, Fusellier M, Camus A, Le Visage C, Guicheux J (2019) Intervertebral disc regeneration: from cell therapy to the development of novel bioinspired endogenous repair strategies. Adv Drug Deliv Rev 146: 306-324.

Crock HV, Yoshizawa H (1976) The blood supply of the lumbar vertebral column. Clin Orthop Relat Res 115: 6-21.

Daly AC, Freeman FE, Gonzalez-Fernandez T, Critchley SE, Nulty J, Kelly DJ (2019) 3D bioprinting for cartilage and osteochondral tissue engineering. Adv Healthc Mater 6: 1700298. DOI: 10.1002/ adhm.201700298.

Danneels LA, Vanderstraeten GG, Cambier DC, Witvrouw EE, De Cuyper HJ, Danneels L (2000) CT imaging of trunk muscles in chronic low back pain patients and healthy control subjects. Eur Spine J 9: 266-272.

DeLucca JF, Cortes DH, Jacobs NT, Vresilovic EJ, Duncan RL, Elliott DM (2016) Human cartilage endplate permeability varies with degeneration and intervertebral disc site. J Biomech 49: 550-557.

Dieleman JL, Cao J, Chapin A, Chen C, Li Z, Liu A, Horst C, Kaldjian A, Matyasz T, Scott KW, Bui AL, Campbell M, Duber HC, Dunn AC, Flaxman AD, Fitzmaurice C, Naghavi M, Sadat N, Shieh P, Squires E, Yeung K, Murray CJL (2020) US health care spending by payer and health condition, 1996-2016. JAMA 323: 863-884.

Dolor A, Sampson SL, Lazar AA, Lotz JC, Szoka FC, Fields AJ (2019) Matrix modification for enhancing the transport properties of the human cartilage endplate to improve disc nutrition. PLoS One 14: e0215218. DOI: 10.1371/journal.pone.0215218.

Dudli S, Sing DC, Hu SS, Berven SH, Burch S, Deviren V, Cheng I, Tay BKB, Alamin TF, Ith MAM, Pietras EM, Lotz JC (2017) ISSLS prize in basic science 2017: intervertebral disc/bone marrow cross-talk with Modic changes. Eur Spine J 26: 1362-1373.

Edwards WT, Zheng Y, Ferrara L, Yuan H (2001) Structural features and thickness of the vertebral cortex in the thoracolumbar spine. Spine (Phila $\mathrm{Pa}$ 1976) 26: 218-225.

Eubanks JD, Lee MJ, Cassinelli E, Ahn NU (2007) Does lumbar facet arthrosis precede disc degeneration? Clin Orthop Relat Res 464: 184-189.

Farshad-Amacker NA, Hughes A, Herzog RJ, Seifert B, Farshad M (2017) The intervertebral disc, the endplates and the vertebral bone marrow as a unit in the process of degeneration. Eur Radiol 27: 2507-2520.

Faur C, Patrascu JM, Haragus H, Anglitoiu B (2019) Correlation between multifidus fatty atrophy and lumbar disc degeneration in low back pain. BMC Musculoskelet Disord 20: 414. DOI: 10.1186/s12891019-2786-7.
Feng Z, Chen L, Hu X, Yang G, Chen Z, Wang Y (2018) Vertebral augmentation can induce early signs of degeneration in the adjacent intervertebral disc: evidence from a rabbit model. Spine (Phila Pa 1976) 43: E1195-E1203.

Fields AJ, Han M, Krug R, Lotz JC (2015) Cartilaginous end plates: quantitative MR imaging with very short echo times - orientation dependence and correlation with biochemical composition. Radiology 274: 482-489.

Fields AJ, Liebenberg EC, Lotz JC (2014a) Innervation of pathologies in the lumbar vertebral end plate and intervertebral disc. Spine J 14: 513-521.

Fields AJ, Rodriguez D, Gary KN, Liebenberg EC, Lotz JC (2014b) Influence of biochemical composition on end plate cartilage tensile properties in the human lumbar spine. J Orthop Res 32: 245-252.

Fields A, Sahli F, Rodriguez A, Lotz J (2012) Seeing double: a comparison of microstructure, biomechanical function, and adjacent disc health between double- and single-layer vertebral endplates. Spine (Phila Pa 1976) 37: E1310-E1317.

Fujiwara A, Tamai K, An HS, Kurihashi A, Lim T-H, Yoshida H, Saotome K (2000) The relationship between disc degeneration, facet joint osteoarthritis, and stability of the degenerative lumbar spine: J Spinal Disord 13: 444-450.

Gawri R, Moir J, Ouellet J, Beckman L, Steffen T, Roughley P, Haglund L (2014a) Physiological loading can restore the proteoglycan content in a model of early IVD degeneration. PLoS One 9: e101233. DOI: 10.1371/journal.pone.0101233.

Gawri R, Rosenzweig DH, Krock E, Ouellet JA, Stone LS, Quinn TM, Haglund L (2014b) High mechanical strain of primary intervertebral disc cells promotes secretion of inflammatory factors associated with disc degeneration and pain. Arthritis Res Ther 16: R21. DOI: 10.1186/ar4449

Grant MP, Epure LM, Bokhari R, Roughley P, Antoniou J, Mwale F (2016) Human cartilaginous endplate degeneration is induced by calcium and the extracellular calcium-sensing receptor in the intervertebral disc. Eur Cell Mater 32: 137-151.

Grayson WL, Chao P-HG, Marolt D, Kaplan DL, Vunjak-Novakovic G (2008) Engineering customdesigned osteochondral tissue grafts. Trends Biotechnol 26: 181-189.

Gruber HE, Gordon B, Norton HJ, Kilburn J, Williams C, Zinchenko N, Heath J, Ingram J, Hanley EN (2008) Analysis of cell death and vertebral end plate bone mineral density in the annulus of the aging sand rat. Spine 8: 475-481.

Gruber HE, Gordon B, Williams C, Norton HJ, Hanley ENJ (2007) Vertebral endplate and disc changes in the aging sand rat lumbar spine: cross-sectional analyses of a large male and female population. Spine (Phila Pa 1976) 32: 2529-2536.

Guehring T, Omlor GW, Lorenz H, Engelleiter K, Richter W, Carstens C, Kroeber M (2006) Disc distraction shows evidence of regenerative potential 
in degenerated intervertebral discs as evaluated by protein expression, magnetic resonance imaging, and messenger ribonucleic acid expression analysis. Spine (Phila Pa 1976) 31: 1658-1665.

Gullbrand SE, Ashinsky BG, Bonnevie ED, Kim DH, Engiles JB, Smith LJ, Elliott DM, Schaer TP, Smith HE, Mauck RL (2018a) Long-term mechanical function and integration of an implanted tissueengineered intervertebral disc. Sci Transl Med 10: eaau0670. DOI: 10.1126/scitranslmed.aau0670.

Gullbrand SE, Peterson J, Ahlborn J, Mastropolo R, Fricker A, Roberts TT, Abousayed M, Lawrence JP, Glennon JC, Ledet EH (2015) ISSLS prize winner: dynamic loading-induced convective transport enhances intervertebral disc nutrition. Spine (Phila Pa 1976) 40: 1158-1164.

Gullbrand SE, Smith LJ, Smith HE, Mauck RL (2018b) Promise, progress, and problems in whole disc tissue engineering. JOR Spine 1: e1015. DOI: 10.1002/jsp2.1015.

Haefeli M, Kalberer F, Saegesser D, Nerlich AG, Boos N, Paesold G (2006) The course of macroscopic degeneration in the human lumbar intervertebral disc. Spine (Phila Pa 1976) 31: 1522-1531.

Hartman RA, Yurube T, Ngo K, Merzlak NE, Debski RE, Brown BN, Kang JD, Sowa GA (2015) Biological responses to flexion/extension in spinal segments ex-vivo. J Orthop Res 33: 1255-1264.

Hayden JA, van Tulder MW, Tomlinson G (2005) Systematic review: strategies for using exercise therapy to improve outcomes in chronic low back pain. Ann Intern Med 142: 776-785.

Henriksson HB, Thornemo M, Karlsson C, Hägg O, Junevik K, Lindahl A, Brisby H (2009) Identification of cell proliferation zones, progenitor cells and a potential stem cell niche in the intervertebral disc region: a study in four species. Spine (Phila Pa 1976) 34: 2278-2287.

Herlin C, Kjaer P, Espeland A, Skouen JS, Leboeuf-Yde C, Karppinen J, Niinimäki J, Sørensen JS, Storheim K, Jensen TS (2018) Modic changes their associations with low back pain and activity limitation: a systematic literature review and metaanalysis. PLoS One 13: e0200677. DOI: 10.1371/ journal.pone.0200677.

Hides J, Gilmore C, Stanton W, Bohlscheid E (2008) Multifidus size and symmetry among chronic LBP and healthy asymptomatic subjects. Man Ther 13: 43-49.

Hodges P, Holm AK, Hansson T, Holm S (2006) Rapid atrophy of the lumbar multifidus follows experimental disc or nerve root injury. Spine (Phila Pa 1976) 31: 2926-2933.

Holm S, Nachemson A (1982) Nutritional changes in the canine intervertebral disc after spinal fusion. Clin Orthop Relat Res 169: 243-258.

Humzah MD, Soames RW (1988) Human intervertebral disc: structure and function. Anat Rec 220: 337-356.
Hung CT, Lima EG, Mauck RL, Taki E, LeRoux MA, Lu HH, Stark RG, Guo XE, Ateshian GA (2003) Anatomically shaped osteochondral constructs for articular cartilage repair. J Biomech 36: 1853-1864.

Illien-Jünger S, Gantenbein-Ritter B, Grad S, Lezuo P, Ferguson SJ, Alini M, Ito K (2010) The combined effects of limited nutrition and high-frequency loading on intervertebral discs with endplates. Spine (Phila Pa 1976) 35: 1744-1752.

Illien-Jünger S, Pattappa G, Peroglio M, Benneker LM, Stoddart MJ, Sakai D, Mochida J, Grad S, Alini M (2012) Homing of mesenchymal stem cells in induced degenerative intervertebral discs in a whole organ culture system. Spine (Phila Pa 1976) 37: 1865-1873.

Imanishi T, Akeda K, Murata K, Sudo A (2019) Effect of diminished flow in rabbit lumbar arteries on intervertebral disc matrix changes using MRI T2mapping and histology. BMC Musculoskelet Disord 20: 347. DOI: 10.1186/s12891-019-2721-y.

Iu J, Massicotte E, Li S-Q, Hurtig MB, Toyserkani E, Santerre JP, Kandel RA (2017a) * In vitro generated intervertebral discs: toward engineering tissue integration. Tissue Eng Part A 23: 1001-1010.

Iu J, Santerre JP, Kandel RA (2017b) Towards engineering distinct multi-lamellated outer and inner annulus fibrosus tissues. J Orthop Res 36: 1346-1355.

James G, Klyne DM, Millecamps M, Stone LS, Hodges PW (2019) ISSLS prize in basic science 2019: physical activity attenuates fibrotic alterations to the multifidus muscle associated with intervertebral disc degeneration. Eur Spine J 28: 893-904.

James G, Millecamps M, Stone LS, Hodges PW (2018) Dysregulation of the inflammatory mediators in the multifidus muscle after spontaneous intervertebral disc degeneration SPARC-null mice is ameliorated by physical activity. Spine (Phila Pa 1976) 43: E1184-E1194.

Jaumard NV, Welch WC, Winkelstein BA (2011) Spinal facet joint biomechanics and mechanotransduction in normal, injury and degenerative conditions. J Biomech Eng 133: 071010. DOI: $10.1115 / 1.4004493$.

Kaiser J, Allaire B, Fein PM, Lu D, Jarraya M, Guermazi A, Demissie S, Samelson EJ, Bouxsein ML, Morgan EF (2018) Correspondence between bone mineral density and intervertebral disc degeneration across age and sex. Arch Osteoporos 13: 123. DOI: 10.1007/s11657-018-0538-1.

Kalichman L, Li L, Kim D, Guermazi A, Berkin V, O’Donnell CJ, Hoffmann U, Cole R, Hunter DJ (2008) Facet joint osteoarthritis and low back pain in the community-based population. Spine (Phila Pa 1976) 33: 2560-2565.

Kang R, Li H, Ringgaard S, Rickers K, Sun H, Chen M, Xie L, Bünger C (2014) Interference in the endplate nutritional pathway causes intervertebral disc degeneration in an immature porcine model. Int Orthop 38: 1011-1017. 
Katz MM, Hargens AR, Garfin SR (1986) Intervertebral disc nutrition. Diffusion versus convection. Clin Orthop Relat Res 210: 243-245.

de Kelft EV (2016) Lumbar facet resurfacing: first experience with the FENIX implant. Clin Spine Surg 29: E475-E481.

Keller T, Ziv I, Moeljanto E, Spengler D (1993) Interdependence of lumbar disc and subdiscal bone properties: a report of the normal and degenerated spine. J Spinal Disord 6: 106-113.

Kim J-S, Ali MH, Wydra F, Li X, Hamilton JL, An HS, Cs-Szabo G, Andrews S, Moric M, Xiao G, Wang JH-C, Chen D, Cavanaugh JM, Im H-J (2015) Characterization of degenerative human facet joints and facet joint capsular tissues. Osteoarthritis Cartilage 23: 2242-2251.

Kirkaldy-Willis WH, Farfan HF (1982) Instability of the lumbar spine. Clin Orthop Relat Res. 165: 110123.

KitanakaS, Takatori R, Arai Y, Nagae M, Tonomura H, Mikami Y, Inoue N, Ogura T, Fujiwara H, Kubo $\mathrm{T}$ (2018) Facet joint osteoarthritis affects spinal segmental motion in degenerative spondylolisthesis. Clin Spine Surg 31: E386-E390.

Korecki CL, MacLean JJ, Iatridis JC (2008) Dynamic compression effects on intervertebral disc mechanics and biology. Spine (Phila Pa 1976) 33: 1403-1409.

Kroeber M, Unglaub F, Guehring T, Nerlich A, Hadi T, Lotz J, Carstens C (2005) Effects of controlled dynamic disc distraction on degenerated intervertebral discs: an in vivo study on the rabbit lumbar spine model. Spine (Phila Pa 1976) 30: 181-187.

Lagerstrand K, Hebelka H, Brisby H (2019) Low back pain patients and controls display functional differences in endplates and vertebrae measured with T2-mapping. Eur Spine J 28: 234-240.

Langrana NA, Kale SP, Edwards WT, Lee CK, Kopacz KJ (2006) Measurement and analyses of the effects of adjacent end plate curvatures on vertebral stresses. Spine J 6: 267-278.

Le Maitre CL, Freemont AJ, Hoyland JA (2007) Accelerated cellular senescence in degenerate intervertebral discs: a possible role in the pathogenesis of intervertebral disc degeneration. Arthritis Res Ther 9: R45. DOI: 10.1186/ar2198.

Li J, Muehleman C, Abe Y, Masuda K (2011) Prevalence of facet joint degeneration in association with intervertebral joint degeneration in a sample of organ donors. J Orthop Res 29: 1267-1274.

Livshits G, Ermakov S, Popham M, MacGregor AJ, Sambrook PN, Spector TD, Williams FMK (2010) Evidence that bone mineral density plays a role in degenerative disc disease: the UK Twin Spine study. Ann Rheum Dis 69: 2102-2106.

Lotz JC, Hadi T, Bratton C, Reiser KM, Hsieh AH (2008) Anulus fibrosus tension inhibits degenerative structural changes in lamellar collagen. Eur Spine J 17: 1149-1159.

Luan S, Wan Q, Luo H, Li X, Ke S, Lin C, Wu Y, Wu S, Ma C (2015) Running exercise alleviates pain and promotes cell proliferation in a rat model of intervertebral disc degeneration. Int J Mol Sci 16: 2130-2144.

Maas H, Noort W, Hodges PW, van Dieën J (2018) Effects of intervertebral disc lesion and multifidus muscle resection on the structure of the lumbar intervertebral discs and paraspinal musculature of the rat. J Biomech 70: 228-234.

MacLean JJ, Lee CR, Grad S, Ito K, Alini M, Iatridis JC (2003) Effects of immobilization and dynamic compression on intervertebral disc cell gene expression in vivo. Spine (Phila Pa 1976) 28: 973-981.

Maidhof R, Jacobsen T, Papatheodorou A, Chahine NO (2014) Inflammation induces irreversible biophysical changes in isolated nucleus pulposus cells. PLoS One 9: e99621. DOI: 10.1371/journal. pone.0099621.

Maroudas A, Stockwell RA, Nachemson A, Urban $\mathrm{J}$ (1975) Factors involved in the nutrition of the human lumbar intervertebral disc: cellularity and diffusion of glucose in vitro. J Anat 120: 113-130.

Martin JT, Gullbrand SE, Kim DH, Ikuta K, Pfeifer CG, Ashinsky BG, Smith LJ, Elliott DM, Smith HE, Mauck RL (2017a) In vitro maturation and in vivo integration and function of an engineered cell-seeded disc-like angle ply structure (DAPS) for total disc arthroplasty. Sci Rep 7: 15765. DOI: 10.1038/s41598017-15887-4.

Martin JT, Kim DH, Milby AH, Pfeifer CG, Smith LJ, Elliott DM, Smith HE, Mauck RL (2017b) In vivo performance of an acellular disc-like angle ply structure (DAPS) for total disc replacement in a small animal model. J Orthop Res 35: 23-31.

Martin JT, Milby AH, Chiaro JA, Kim DH, Hebela NM, Smith LJ, Elliott DM, Mauck RL (2014) Translation of an engineered nanofibrous disc-like angle-ply structure for intervertebral disc replacement in a small animal model. Acta Biomater 10: 2473-2481.

Martins DE, Medeiros VP de, Wajchenberg M, Paredes-Gamero EJ, Lima M, Reginato RD, Nader HB, Puertas EB, Faloppa F (2018) Changes in human intervertebral disc biochemical composition and bony end plates between middle and old age. PLoS One 13: e0203932. DOI: 10.1371/journal.pone.0203932.

McAfee P, Khoo LT, Pimenta L, Capuccino A, Sengoz A, Coric D, Hes R, Conix B, Asgarzadie F, Hamzaoglu A, Mirofsky Y, Anekstein Y (2007) Treatment of lumbar spinal stenosis with a total posterior arthroplasty prosthesis: implant description, surgical technique, and a prospective report on 29 patients. Neurosurg Focus 22: E13. DOI: 10.3171/ foc.2007.22.1.13.

Miller BF, Olesen JL, Hansen M, Døssing S, Crameri RM, Welling RJ, Langberg $\mathrm{H}$, Flyvbjerg A, Kjaer M, Babraj JA, Smith K, Rennie MJ (2005) Coordinated collagen and muscle protein synthesis in human patella tendon and quadriceps muscle after exercise. J Physiol 567: 1021-1033.

Mitchell UH, Bowden JA, Larson RE, Belavy DL, Owen PJ (2020) Long-term running in middle-aged 
men and intervertebral disc health, a cross-sectional pilot study. PLoS One 15: e0229457. DOI: 10.1371/ journal.pone.0229457.

Molinos M, Almeida CR, Caldeira J, Cunha C, Gonçalves RM, Barbosa MA (2015) Inflammation in intervertebral disc degeneration and regeneration. J R Soc Interface 12: 20150429. DOI: 10.1098/ rsif.2015.0429.

Montazel J-L, Divine M, Lepage E, Kobeiter H, Breil S, Rahmouni A (2003) Normal spinal bone marrow in adults: dynamic gadolinium-enhanced MR imaging. Radiology 229: 703-709.

Moore RJ, Vernon-Roberts B, Osti OL, Fraser RD (1996) Remodeling of vertebral bone after outer anular injury in sheep. Spine (Phila Pa 1976) 21: 936940.

Moriguchi Y, Mojica-Santiago J, Grunert P, Pennicooke B, Berlin C, Khair T, Navarro-Ramirez R, Ricart Arbona RJ, Nguyen J, Härtl R, Bonassar LJ (2017) Total disc replacement using tissue-engineered intervertebral discs in the canine cervical spine. PLoS One 12: e0185716. DOI: 10.1371/journal.pone.0185716.

Nabeshima Y, Grood ES, Sakurai A, Herman JH (1996) Uniaxial tension inhibits tendon collagen degradation by collagenase in vitro. J Orthop Res 14: 123-130.

Nachemson A, Lewin T, Maroudas A, Freeman MA (1970) In vitro diffusion of dye through the endplates and the annulus fibrosus of human lumbar inter-vertebral discs. Acta Orthop Scand 41: 589-607.

Nerurkar NL, Sen S, Huang AH, Elliott DM, Mauck RL (2010) Engineered disc-like angle-ply structures for intervertebral disc replacement. Spine (Phila Pa 1976) 35: 867-873.

Netzer C, Distel P, Wolfram U, Deyhle H, Jost GF, Schären S, Geurts J (2018) Comparative analysis of bone structural parameters reveals subchondral cortical plate resorption and increased trabecular bone remodeling in human facet joint osteoarthritis. Int J Mol Sci 19: 845. DOI: 10.3390/ijms19030845.

Nosikova YS, Santerre JP, Grynpas M, Gibson G, Kandel RA (2012) Characterization of the annulus fibrosus-vertebral body interface: identification of new structural features. J Anat 221: 577-589.

Oki S, Matsuda Y, Shibata T, Okumura H, Desaki J (1996) Morphologic differences of the vascular buds in the vertebral endplate: scanning electron microscopic study. Spine (Phila Pa 1976) 21: 174-177.

O'Leary SA, Paschos NK, Link JM, Klineberg EO, Hu JC, Athanasiou KA (2018) Facet joints of the spine: structure-function relationships, problems and treatments, and the potential for regeneration. Annu Rev Biomed Eng 20: 145-170.

Paholpak P, Dedeogullari E, Lee C, Tamai K, Barkoh K, Sessumpun K, Wang JC, Buser Z (2018) Do modic changes, disc degeneration, translation and angular motion affect facet osteoarthritis of the lumbar spine. Eur J Radiol 98: 193-199.

Parkkola R, Rytökoski U, Kormano M (1993) Magnetic resonance imaging of the discs and trunk muscles in patients with chronic low back pain and healthy control subjects. Spine (Phila Pa 1976) 18: 830-836.

Patil P, Niedernhofer LJ, Robbins PD, Lee J, Sowa G, Vo N (2018) Cellular senescence in intervertebral disc aging and degeneration. Curr Mol Biol Rep 4: 180-190.

Paul CPL, Zuiderbaan HA, Zandieh Doulabi B, van der Veen AJ, van de Ven PM, Smit TH, Helder MN, van Royen BJ, Mullender MG (2012) Simulatedphysiological loading conditions preserve biological and mechanical properties of caprine lumbar intervertebral discs in ex vivo culture. PLoS One 7: e33147. DOI: 10.1371/journal.pone.0033147.

Peredo AP, Gullbrand SE, Smith HE, Mauck RL (2020) Putting the pieces in place: mobilizing cellular players to improve annulus fibrosus repair. Tissue Eng Part B Rev Online ahead of print. DOI: 10.1089/ ten.TEB.2020.0196.

Pereira CL, Gonçalves RM, Peroglio M, Pattappa G, D'Este M, Eglin D, Barbosa MA, Alini M, Grad $S$ (2014) The effect of hyaluronan-based delivery of stromal cell-derived factor-1 on the recruitment of MSCs in degenerating intervertebral discs. Biomaterials 35: 8144-8153.

Pereira CL, Teixeira GQ, Ribeiro-Machado C, Caldeira J, Costa M, Figueiredo F, Fernandes R, Aguiar P, Grad S, Barbosa MA, Gonçalves RM (2016) Mesenchymal stem/stromal cells seeded on cartilaginous endplates promote intervertebral disc regeneration through extracellular matrix remodeling. Sci Rep 6: 33836. DOI: 10.1038/srep33836.

Petersen AMW, Pedersen BK (2005) The antiinflammatory effect of exercise. J Appl Physiol 98: 1154-1162.

Phillips FM, Tzermiadianos MN, Voronov LI, Havey RM, Carandang G, Renner SM, Rosler DM, Ochoa JA, Patwardhan AG (2009) Effect of the total facet arthroplasty system after complete laminectomy-facetectomy on the biomechanics of implanted and adjacent segments. Spine J 9: 96-102.

Ploumis A, Michailidis N, Christodoulou P, Kalaitzoglou I, Gouvas G, Beris A (2011) Ipsilateral atrophy of paraspinal and psoas muscle in unilateral back pain patients with monosegmental degenerative disc disease. Br J Radiol 84: 709-713.

Pye SR (2006) Radiographic features of lumbar disc degeneration and bone mineral density in men and women. Ann Rheum Dis 65: 234-238.

Raj PP (2008) Intervertebral disc: anatomyphysiology-pathophysiology-treatment. Pain Pract 8: 18-44.

Roberts S, Menage J, Duance V, Wotton S, Ayad S (1991) 1991 Volvo award in basic sciences. Collagen types around the cells of the intervertebral disc and cartilage end plate: an immunolocalization study. Spine (Phila Pa 1976) 16: 1030-1038.

Roberts S, Menage J, Urban JPG (1989) Biochemical and structural properties of the cartilage end-plate and its relation to the intervertebral disc. Spine (Phila Pa 1976) 14: 166-174. 
Rodrigues SA, Thambyah A, Broom ND (2015) A multiscale structural investigation of the annulusendplate anchorage system and its mechanisms of failure. Spine J 15: 405-416.

Rodrigues SA, Wade KR, Thambyah A, Broom ND (2012) Micromechanics of annulus-end plate integration in the intervertebral disc. Spine J 12: 143150.

Rodriguez AG, Rodriguez-Soto AE, Burghardt AJ, Berven S, Majumdar S, Lotz JC (2012) Morphology of the human vertebral endplate. J Orthop Res 30: 280-287.

Rodriguez AG, Slichter CK, Acosta FL, RodriguezSoto AE, Burghardt AJ, Majumdar S, Lotz JC (2011) Human disc nucleus properties and vertebral endplate permeability. Spine (Phila Pa 1976) 36: 512520.

Rolander SD, Blair WE (1975) Deformation and fracture of the lumbar vertebral end plate. Orthop Clin North Am 6: 75-81.

Rutges JPHJ, Jagt van der OP, Oner FC, Verbout AJ, Castelein RJM, Kummer JA, Weinans H, Creemers LB, Dhert WJA (2011) Micro-CT quantification of subchondral endplate changes in intervertebral disc degeneration. Osteoarthritis Cartilage 19: 89-95.

Sakai D, Nakamura Y, Nakai T, Mishima T, Kato S, Grad S, Alini M, Risbud MV, Chan D, Cheah KSE, Yamamura K, Masuda K, Okano H, Ando K, Mochida J (2012) Exhaustion of nucleus pulposus progenitor cells with ageing and degeneration of the intervertebral disc. Nat Commun 3: 1264. DOI: 10.1038/ncomms2226.

Sampson SL, Sylvia M, Fields AJ (2019) Effects of dynamic loading on solute transport through the human cartilage endplate. J Biomech 83: 273-279.

Sasaki N, Henriksson HB, Runesson E, Larsson K, Sekiguchi M, Kikuchi S, Konno S, Rydevik B, Brisby H (2012) Physical exercise affects cell proliferation in lumbar intervertebral disc regions in rats: Spine (Phila Pa 1976) 37: 1440-1447.

Schroeder GD, Markova DZ, Koerner JD, Rihn JA, Hilibrand AS, Vaccaro AR, Anderson DG, Kepler CK (2017) Are Modic changes associated with intervertebral disc cytokine profiles? Spine J 17: 129134.

Shahidi B, Gibbons MC, Esparza M, Zlomislic V, Allen RT, Garfin SR, Ward SR (2020) Cell populations and muscle fiber morphology associated with acute and chronic muscle degeneration in lumbar spine pathology. JOR Spine 3: e1087. DOI: 10.1002/ jsp2.1087.

Shahtahmassebi B, Hebert JJ, Stomski NJ, Hecimovich M, Fairchild TJ (2014) The effect of exercise training on lower trunk muscle morphology. Sports Med 44: 1439-1458.

Shamji MF, Setton LA, Jarvis W, So S, Chen J, Jing L, Bullock R, Isaacs RE, Brown C, Richardson WJ (2010) Proinflammatory cytokine expression profile in degenerated and herniated human intervertebral disc tissues. Arthritis Rheum 62: 1974-1982.
Simpson EK, Parkinson IH, Manthey B, Fazzalari NL (2001) Intervertebral disc disorganization is related to trabecular bone architecture in the lumbar spine. J Bone Miner Res 16: 681-687.

Sjovold SG, Zhu Q, Bowden A, Larson CR, de Bakker PM, Villarraga ML, Ochoa JA, Rosler DM, Cripton PA (2012) Biomechanical evaluation of the Total Facet Arthroplasty System ${ }^{\circledR}$ (TFAS $^{\circledR}$ ): loading as compared to a rigid posterior instrumentation system. Eur Spine J 21: 1660-1673.

Sloan SR, Lintz M, Hussain I, Hartl R, Bonassar LJ (2018) Biologic annulus fibrosus repair: a review of preclinical in vivo investigations. Tissue Eng Part B Rev 24: 179-190.

Suri P, Miyakoshi A, Hunter DJ, Jarvik JG, Rainville J, Guermazi A, Li L, Katz JN (2011) Does lumbar spinal degeneration begin with the anterior structures? A study of the observed epidemiology in a community-based population. BMC Musculoskelet Disord 12: 202. DOI: 10.1186/1471-2474-12-202.

Tang G, Zhou B, Li F, Wang W, Liu Y, Wang X, Liu C, Ye X (2020) Advances of naturally derived and synthetic hydrogels for intervertebral disk regeneration. Front Bioeng Biotechnol 8: 745. DOI: 10.3389/fbioe.2020.00745.

Teichtahl AJ, Urquhart DM, Wang Y, Wluka AE, O'Sullivan R, Jones G, Cicuttini FM (2016) Lumbar disc degeneration is associated with modic change and high paraspinal fat content - a 3.0T magnetic resonance imaging study. BMC Musculoskelet Disord 17: 439. DOI: 10.1186/s12891-016-1297-z.

Tendulkar G, Chen T, Ehnert S, Kaps H-P, Nüssler AK (2019) Intervertebral disc nucleus repair: hype or hope? Int J Mol Sci 20: 3622. DOI: 10.3390/ ijms20153622.

Thompson JP, Pearce RH, Schechter MT, Adams ME, Tsang IK, Bishop PB (1990) Preliminary evaluation of a scheme for grading the gross morphology of the human intervertebral disc. Spine (Phila Pa 1976) 15: 411-415.

Urban JP, Holm S, Maroudas A, Nachemson A (1977) Nutrition of the intervertebral disk. An in vivo study of solute transport. Clin Orthop Relat Res 129: 101-114.

Urban JP, Holm S, Maroudas A, Nachemson A (1982) Nutrition of the intervertebral disc: effect of fluid flow on solute transport. Clin Orthop Relat Res 170: 296-302.

Urrutia J, Besa P, Lobos D, Campos M, Arrieta C, Andia M, Uribe S (2018) Lumbar paraspinal muscle fat infiltration is independently associated with sex, age, and inter-vertebral disc degeneration in symptomatic patients. Skeletal Radiol 47: 955-961.

Vadalà G, Russo F, Pattappa G, Schiuma D, Peroglio M, Benneker LM, Grad S, Alini M, Denaro V (2013) The transpedicular approach as an alternative route for intervertebral disc regeneration. Spine (Phila Pa 1976) 38: E319-E324.

Veres SP, Robertson PA, Broom ND (2010) ISSLS prize winner: how loading rate influences disc failure 
mechanics: a microstructural assessment of internal disruption. Spine (Phila Pa 1976) 35: 1897-1908.

Wade KR, Robertson PA, Broom ND (2011) A fresh look at the nucleus-endplate region: new evidence for significant structural integration. Eur Spine J 20: 1225-1232.

Walsh AJL, Lotz JC (2004) Biological response of the intervertebral disc to dynamic loading. J Biomech 37: 329-337.

Wang L, Han M, Wong J, Zheng P, Lazar AA, Krug R, Fields AJ (2021) Evaluation of human cartilage endplate composition using MRI: spatial variation, association with adjacent disc degeneration, and in vivo repeatability. J Orthop Res Online ahead of print. DOI: 10.1002/jor.24787.

Wang Y, Battié MC, Boyd SK, Videman T (2011) The osseous endplates in lumbar vertebrae: Thickness, bone mineral density and their associations with age and disk degeneration. Bone 48: 804-809.

Wangler S, Menzel U, Li Z, Ma J, HoppeS, Benneker LM, Alini M, Grad S, Peroglio M (2019) CD146/ MCAM distinguishes stem cell subpopulations with distinct migration and regenerative potential in degenerative intervertebral discs. Osteoarthritis Cartilage 27: 1094-1105.

Welch N, Moran K, Antony J, Richter C, Marshall B, Coyle J, Falvey E, Franklyn-Miller A (2015) The effects of a free-weight-based resistance training intervention on pain, squat biomechanics and MRIdefined lumbar fat infiltration and functional crosssectional area in those with chronic low back. BMJ Open Sport Exerc Med 1: e000050. DOI: 10.1136/ bmjsem-2015-000050.

Wilke H-J, Schmidt H, Werner K, Schmölz W, Drumm J (2006) Biomechanical evaluation of a new total posterior-element replacement system. Spine (Phila Pa 1976) 31: 2790-2796.

Wong J, Sampson SL, Bell-Briones H, Ouyang A, Lazar AA, Lotz JC, Fields AJ (2019) Nutrient supply and nucleus pulposus cell function: effects of the transport properties of the cartilage endplate and potential implications for intradiscal biologic therapy. Osteoarthritis Cartilage 27: 956-964.

Wu Y, Cisewski SE, Wegner N, Zhao S, Pellegrini VD, Slate EH, Yao H (2016) Region and straindependent diffusivities of glucose and lactate in healthy human cartilage endplate. J Biomech 49: 2756-2762.

Wuertz K, Godburn K, MacLean JJ, Barbir A, Donnelly JS, Roughley PJ, Alini M, Iatridis JC (2009) In vivo remodeling of intervertebral discs in response to short- and long-term dynamic compression. J Orthop Res 27: 1235-1242.

Xiao Z, He J, Su G, Chen M, Hou Y, Chen S, Lin D (2018) Osteoporosis of the vertebra and osteochondral remodeling of the end plate causes intervertebral disc degeneration in ovariectomized mice. Arthritis Res Ther 20: 207. DOI: 10.1186/s13075-018-1701-1.

Yin S, Du H, Zhao W, Ma S, Zhang M, Guan M, Liu M (2019) Inhibition of both endplate nutritional pathways results in intervertebral disc degeneration in a goat model. J Orthop Surg Res 14: 138. DOI: 10.1186/s13018-019-1188-8.

Yu B, Jiang K, Li X, Zhang J, Liu Z (2017) Correlation of the features of the lumbar multifidus muscle with facet joint osteoarthritis. Orthopedics 40: e793-e800.

Zehra U, Robson-Brown K, Adams MA, Dolan $P$ (2015) Porosity and thickness of the vertebral endplate depend on local mechanical loading. Spine (Phila Pa 1976) 40: 1173-1180.

Zhang Y-H, Zhao C-Q, Jiang L-S, Chen X-D, Dai L-Y (2008) Modic changes: a systematic review of the literature. Eur Spine J 17: 1289-1299.

Zhao F-D, Pollintine P, Hole BD, Adams MA, Dolan P (2009) Vertebral fractures usually affect the cranial endplate because it is thinner and supported by less-dense trabecular bone. Bone 44: 372-379.

Zhu Q, Larson CR, Sjovold SG, Rosler DM, Keynan O, Wilson DR, Cripton PA, Oxland TR (2007) Biomechanical evaluation of the Total Facet Arthroplasty System: 3-dimensional kinematics. Spine (Phila Pa 1976) 32: 55-62.

\section{Discussion with Reviewer}

Reviewer 1: How could studies investigating the crosstalk between spinal tissues during degeneration and regeneration be designed and what would the different models be able to address?

Authors: Studying the mechanisms of crosstalk between spinal tissues during degeneration in human patients can be challenging; as such, models of disease will be essential for studying degeneration and regeneration from a motion segment perspective. There are a wide variety of existing animal models where the time course of disc degeneration is well characterised, yet degenerative changes to other spinal structures remain unknown. Particularly in large animals, where size scales of the spinal tissues are closer to those of humans, these existing disc degeneration models may also be utilised to study concomitant degenerative changes to the paraspinal muscles and facet joints. Alternately, in vivo models of facet degeneration could be established, for example, by injection of catabolic agents, and utilised to study the effects on the disc and paraspinal muscles. When these animal models are then utilised to evaluate the efficacy of regenerative therapeutics for the disc, it will also be important to assess any secondary regenerative effects on adjacent spinal tissues. Organ culture or co-culture models could also be utilised, potentially using human tissue, to investigate more acute effects or biological mechanisms of crosstalk.

Reviewer 1: What type of treatment you envision for the treatment of degeneration of a whole motion segment?

Authors: An improved understanding of disease aetiology as well as enhanced diagnostics will be critical for advancing whole-motion segment- 
centric treatments. Identifying in each patient which component of the motion segment contributes most significantly to the degenerative cascade will allow clinicians to better guide treatment. For patients with early-stage disease, treatment approaches which may have a regenerative effect on all-motion-segment components could be utilised, such as exercise- or physical-therapy regimens. For patients with more advanced disease, combination treatments may need to be considered to maximise regeneration and reduction in pain. For example, a patient may not need to receive only a stem cell, hydrogel or growth factor injection into their disc, but also into the facet joint to alleviate painful symptoms originating from that source. As tissue engineering technologies advance, patients may also be able to receive not only a tissue engineered disc replacement, but also a tissue engineered facet replacement as well.

Editor's note: The Guest Editor responsible for this paper was Zhen Li. 